\title{
A Field Investigation on a Group of Morning Runners
}

\author{
Wu Dezhou ${ }^{1}$, Xia Chengqian ${ }^{2, ~ * ~}$ \\ ${ }^{1}$ Department of Social Sports, Yancheng Teachers University, Yancheng, China \\ ${ }^{2}$ School of Sports Science, Nantong University, Nantong, China \\ Email address: \\ 615966477@qq.com (Wu Dezhou),xiachengqian@ntu.edu.cn (Xia Chengqian) \\ *Corresponding author
}

\section{To cite this article:}

Wu Dezhou, Xia Chengqian. A Field Investigation on a Group of Morning Runners. International Journal of Sports Science and Physical Education. Vol. 5, No. 4, 2020, pp. 41-45. doi: 10.11648/j.ijsspe.20200504.11

Received: November 20, 2020; Accepted: December 2, 2020; Published: December 11, 2020

\begin{abstract}
The background of this article comes from the marathon craze in China. The main purpose of this paper is to analyze the common people's morning exercise behavior, reveal the motivation and social background behind people's running phenomenon, and provide reasonable suggestions for national fitness. This paper makes a long-term follow-up observation on the morning exercise activities and competition behaviors of a group of runners, by using sociological and anthropological research methods such as field investigation and deep description. This paper deeply depicts the group image of mass runners, describes the different mentality of different runners when they run and participate in competitions, reveals the social background and deep-seated motivation of mass fitness in the new era, so as to improve public fitness behavior and cultivate public fitness, to provide reference and suggestions for further promoting the construction of healthy China. The conclusion of this paper shows that stable material living conditions are the main cause of the upsurge of running and the paired running behavior reflects the fact that people's purpose of running is not only to keep fit or exercise, but also to meet the needs of people's social interaction.
\end{abstract}

Keywords: Running, Group, Marathon, Fieldwork, Deep Description

\section{Introduction}

Since the 18th National Congress of the Communist Party of China, with the process of building a well-off society in an all-round way, with the improvement of living standards of urban and rural people and the increase of leisure time, especially the lowering of the threshold of marathon race, and the planning and promotion of all levels of government and various road running event organizations, running has become the most important means of public fitness. Proper morning running is the "source of vitality" [1], the first start of a day's activities, with "switching effect" [2]. Light morning running can make people full of vigor and vitality, reduce anxiety and improve sleep quality. After morning running, taking a bath, having breakfast and going to work can not only enhance physical strength, but also promote quick thinking, which helps to improve work efficiency. In addition, morning running is conducive to the formation of good living habits, many friends take morning running as a means to develop the habit of early bed and early rise and improve the quality of life.
The community where I live is close to the playground of a university. The playground is close to the west gate of the University, so it is called the playground of the west. Because it is close to the school gate, it is easy to get in and out, so there will be a large group of residents and teachers running here every morning, forming a morning running group. It took me more than three years from curiosity at the beginning to joining the group and conducting a follow-up survey on this group of runners. My purpose is to faithfully present small facts in a deep way [3], and let the facts speak, so as to achieve the "meaning interpretation and deep analysis" [4], standing in the "circle" From the perspective of "people", we can understand the behavior of runners, draw reasonable conjectures, and let readers understand "what happened there" and "what kind of people are they" [5]. This group's attitude and habit of running exercise reflects the common people's understanding and cognition of public fitness, which arouses our strong interest. The survey report is arranged as follows, hoping to provide useful reference for national fitness and healthy China construction. 


\section{The Group Statue of Morning Runners}

There are about 50 people (excluding students) who take part in morning running or walking on the playground of this school every day. Some enthusiasts have formed a wechat group, which is named "Y City running bar" by borrowing the name of the city. However, there are more than 30 people who insist on morning running for a long time. The relatively fixed group can be divided into three types: The first one is a group with fast speed, including Champion Zhang, Black Leopard, Captain Cai, Niu Chun, Ah Jun, Zhengshun, Zhengfu, Lanfang, Binhai, Xiaoman, Jianming, etc. The group with medium running speed includes Wei Dong, grandpa Bian, Mr. Fu, Mrs. Wang, Lao Qian and Professor Chen, police officer Yang, sister Meng, grandma Zhou, and a group of people who run slowly, such as Legal-medico physician Hou, Wang Zong, Xiaomei, Dai, Headmaster Huang, PhD Xia, etc. The first two groups run faster and come early every day. They usually arrive at about 5:30 and leave the playground at about 6:30 and go home to wash and go to work. The latter group runs slowly and comes late every day, usually arriving at about 6:00 and evacuating around 7:00. This refers to the spring and summer season. If it is autumn and winter, it will be delayed by about half an hour because it is late. No matter which group of people, the total running time is about 1 hour every day, and the total mileage of slow running is about 7-8 kilometers. The total running distance of fast and medium speed people is about 10 kilometers every day.

The morning joggers come from various walks of life. There are school teachers (such as Mr. Fu, Mrs. Wang, Professor Chen, Xiao Mei, Headmaster Huang, and PhD Xia), police officers of the public security system (such as Zhengfu, police officer Yang, and Legal-medico physician Hou), employees of banks and architectural design institutes (such as Weidong and Jianming), real estate agents and stock market intermediaries (such as Binhai, Laoqian, Dai), and employers and freelancers (such as Zhengshun, Lanfang and Champion Zhang, Black Leopard, Captain Cai, Niu Chun, Ah Jun, Xiaoman) and retired comrades (such as Mr. Wang, Grandpa Bian, sister Meng, and grandma Zhou). The age span is also relatively large, mainly middle-aged and elderly. In summer, every morning around 5 o'clock, there will be morning running figures on the playground. Some people who get up early even come to the playground at 4:30. It is mainly the older people, some of whom are retired teachers of this school, and the gatekeepers are not in a position to interfere. In summer, the sun rises very early, and the sun at more than 6 o'clock is relatively dry. Therefore, the old teachers come to the playground early and take a walk in circles. And those young students, who should be vigorous [6], are rarely seen on the playground in the morning.

This group of runners have two common characteristics. One is that they have plenty of spare time. Even those working in the public security and banking systems, their working hours are after 8:30 in the morning, so they have enough time for morning running. This also shows that time is the most important factor in the morning running participants. Second, they have relatively stable income and have no worries about food and clothing. If you have free money, you will have the leisure of running [7]. If you have leisure time, you can always insist on running. Therefore, under the background of building a well-off society in an all-round way in the new era, leisure is the internal cause and spiritual basis for running leisurely, and leisure money is the external cause and material basis for the formation of running habits. Therefore, we must eulogize our new era. Without a stable material life, it is impossible to form a nationwide running craze.

\section{Enthusiastic Organizer}

Captain Cai is one of the original initiators of this group. He is a warm-hearted person. Every time he goes out to participate in the marathon race, he takes the role of organizer and server, just like the leader of the official Y City Marathon team, so everyone likes to call him Captain CAI. He often publishes the registration information of a marathon race in the running group to remind those who have time and interest to register and pay by relay in the wechat group. Then he will collect the information of the applicants and apply to the organizing committee. After that, he will help you contact the vehicles to the competition city, as well as accommodation and dining places. He is very considerate. Before each competition, he will collect a part of the fee in advance to book transportation and meals and accommodation during the competition. After the competition, he will publish the income and expenditure in the group in time, and the expenses will be refunded and the expenses will be compensated in an open and transparent manner. So it won the trust of running friends.

As a running group organizer, generally should have the following conditions. First of all, there is a zeal to serve you and has a good popularity; secondly, it is practical and rigorous in doing things, which can be relied on and trusted by everyone; thirdly, the running performance is $\mathrm{OK}$ and has certain running strength, which makes everyone admire. And Captain Cai just has these points. So in recent years, every time there are large-scale marathon events, we will urge Captain Cai to come forward to organize. And going out to participate in the marathon race with Captain Cai, has become the running friends enjoy talking about fun. All of us are traveling together at our own expense, chatting and laughing along the way, exchanging their own running experience. When we stay, we are basically two or three people in a room, making a lot of noise together and reminding each other of the matters needing attention. When running, they encourage each other, and those who run at the same speed will advance side by side and take care of each other. After the race, everyone went back to the hotel, took a bath, changed into clean clothes, and went to the predetermined restaurant for dinner and drink. Captain Cai would bring a box of white wine every time he went out for the competition. He would take a few more cases of beer in the hotel. If he liked to drink liquor, he would drink beer if he liked to drink beer, and if he didn't like drinking, he would drink some. Everyone would take what he wanted and have fun. 


\section{The Paired Running Behaviour}

Professor Chen is in his early $40 \mathrm{~s}$. He is $165 \mathrm{~cm}$ tall and weighs $80 \mathrm{~kg}$. He is still a little puffy, but he is much better than before he didn't form a running habit in the past. He has been running in the morning for two years, and his weight has reached $92 \mathrm{~kg}$ before starting the morning running exercise. The main purpose of his morning running is to lose weight. Through two years of unremitting efforts, the effect of weight loss is obvious. He is still stocky, but his face and legs are not as rough as they were two years ago. Professor Chen is a math teacher. It is said that he was the number one science student in his county during the college entrance examination, and his county is still a famous college in the province. Professor Chen's appearance also looks very intelligent, broad forehead, a pair of wide glasses, at any time is a smiling appearance, seems to be ready to give us a math class. He also talked about astronomy, geography, national affairs, politics, finance, health care, and even food, men and women. Every day, Professor Chen publishes some current affairs news in his running friends circle. When he runs on the playground, he is also a news spokesman. He talks about all kinds of anecdotes and family background, so that you can forget the loneliness and loneliness of running. Professor Chen likes to run with younger girls like Xiaomei. He talks while running, sometimes smiling, sometimes forgetting to laugh, which has endless fun.

Xiaomei is a teacher in a middle school nearby. She doesn't like talking very much. When she runs, she is always smiling, tender and charming. As a middle school teacher, relatively speaking, there are more classes, so it is not every day to run on the playground. When she didn't come, Professor Chen was lonely and couldn't mention running spiritually. She just walked slowly around the playground. How much did he run today? He said listlessly that he just took a walk today, rest and adjust.

In the usual running exercise or going out to participate in marathons, there are many such running in pairs, and there are also three or five people running in small groups. Some of them are heterosexual (such as Professor Chen and Xiaomei, Zhengfu and Lanfang, Mr. Fu and Mrs. Wang), some are of the same sex; some are close friends, some are colleagues or classmates, some are husband and wife or lovers.

There are two reasons for running in groups: one is that they have a good relationship with each other and have a common language and common topics. Running together is conducive to relieving loneliness and improving the fun of running; the other is that everyone runs at a relatively close speed, and there is no such phenomenon as I wait for you or you chase me. Running with partners can encourage and care for each other, which is conducive to advancing side by side and completing the arduous running together.

The paired running behavior reflects the fact that people's purpose of running is not only to keep fit or exercise, but also to meet the needs of people's social interaction. Human beings are social animals, and they always have the desire and demand for communication [8]. Associating with groups and living in groups can give people a sense of existence and achievement, which is also the reason why many people are keen on participating in marathon. The carnival scene of ten thousand people in the marathon scene will make people strongly experience the tension and heat of the group. Running together makes people more confident to face the challenge of long and hard running. Of course, running is a kind of personalized behavior, some people like to walk alone, more people like to be lively. The behavior of running with partners reflects the diversity of mass running.

\section{Old and Strong Runners}

Grandpa Bian is more than 70 years old, who is the oldest runner on the playground. Every morning, he runs 25 laps along the playground, with a distance of more than $10 \mathrm{~km}$. His main purpose of participating in the morning run is to kill time. He's not fat, he doesn't have any diseases, he doesn't have the usual reasons for running. More than 10 years ago, when he just retired from the port authority of Y City, he used to kill his retirement life by participating in badminton activities. However, people who played badminton with Grandpa Bian often played early and at a fixed time. He went to the stadium at more than 5 a. m. and went home to take a bath and go to work at 7 o'clock. Badminton is a sport that requires at least two people to play together. After 7 o'clock in the morning, Grandpa Bian's badminton training is getting better. In this period of time, he can't find a suitable partner to match. In the long run, he feels it's hard to enjoy himself, and the effect of exercise and entertainment is not enough. Therefore, Grandpa Bian changes to morning running. He thinks it's more free and easier to play than badminton Special equipment, also do not have to find a companion or opponent. You can run in a group or on your own. You can run fast or slow, early or late, regardless of the time limit. You can run freely on the playground whether it is 7 o'clock or 8 o'clock.

Like most cities in China, there are more middle-aged and elderly people running or walking on the playground [9]. Most of the old teachers come for a walk, because they are more rational exercisers, and the amount of exercise is moderate. There are also a few elderly people in the surrounding residential areas who like running, because they have formed a habit and formed a lifestyle. Besides Grandpa Bian, there are also Grandma Zhou and sister Meng. Grandpa Bian and grandma Zhou are senior runners who have been running on the playground for many years. Elder sister Meng is in her 60s. She has not been running for a long time. She has been running for nearly a year. Her son has already worked and her grandson has gone to school. Her husband has taken care of the business of buying vegetables and cooking. Therefore, she has more free time every morning. She is a lively person. At first, she went to the playground for a walk and talked to people. Later, she saw that the people who ran together were chatting, laughing and making fun of each other. She felt very interesting and curious, so she joined in and became addicted to running. When she heard Captain Cai, Wei Dong and others introducing interesting news and information about the 
marathon race, she signed up for the Wuxi Marathon just like others. Originally, elder sister Meng was a little worried and didn't dare to run. Later, with the support and encouragement of her husband and son, the family took a spring travelling and drove a car to Wuxi to participate in the cherry blossom appointment. Accompanied by Wei Dong, Phd Xia and other friends, sister Meng successfully completed the Wuxi marathon. At this time, she became more confident and signed up for the Beijing marathon. Unexpectedly, she won the bid. So sister Meng and her husband came to Beijing again. In Tian-an-men Square, she witnessed and participated in the singing of the National Anthem by tens of thousands of people. I can't believe there are so many benefits to running. Since then, sister Meng has to run a few kilometers in the playground every morning. Her purpose is very simple. She has physical strength to travel! For her, going out for the marathon is just a reason and a ritual for her to travel. As for the results, Meng said with a smile, "I never care about the results. I just want to go to the track of a certain city in person for a walk and run, rather than sit in the van to see the scenery."

A lot of scholars have observed and studied the phenomenon that the proportion of the elderly in the morning exercise group is high. Many people believe that the main reason why the elderly people participate in exercise more than the young people, especially in the morning exercise, is that the elderly have a higher demand for health [10]. In the author's opinion, different age groups have high demand for health, and the main reason why the elderly participate in morning exercise more lies in the time factor and the resulting lifestyle. Most of the elderly have formed a healthy lifestyle of going to bed early and getting up early [11]. Moreover, the elderly have more time than the young people, so they don't have to rush to work. Therefore, the elderly can do morning exercises or go out to participate in tourism events in their own way.

\section{Conclusion}

The running group we are tracking and investigating is just a microcosm of thousands of runners across the country. It reflects the fact that without a stable material life, it is impossible to form a nationwide running craze. When you have free time, you can have free money to have the leisure of running. Under the background of building a well-off society in an all-round way in the new era, leisure is the internal cause and spiritual basis for running leisurely, and leisure money is the material basis for the formation of running habits. Therefore, we must warmly eulogize our new era.

The participants of the running group have two common characteristics. One is that they have plenty of spare time. This also shows that time is the most important factor in the morning running participants. Second, they have relatively stable income, which shows that with the completion of an all-round well-off society in the new era, the middle class occupies the vast majority in China's social system structure. This is exactly the material basis for the formation of a nationwide upsurge in running or fitness. The popularity of household water heater, the promotion of various portable wearable running equipment, the improvement of fitness trails and health facilities along the way are the inducing conditions for people to participate in running exercise, which are all formed on this material basis.

The paired running behavior reflects the fact that people's purpose of running is not only to keep fit or exercise, but also to meet the needs of people's social interaction. All the contestants will be treated like heroes, and all the competitors will feel the pride of being respected, which greatly satisfies people's self-esteem. It's also the motivation of many people who are keen on running marathons. There are two reasons for running in groups: one is that they have a good relationship with each other and have a common language and common topics. Running together is conducive to relieving loneliness and improving the fun of running; the other is that running at a relatively close speed can encourage and take care of each other, which is conducive to advancing side by side and completing the arduous running together.

The main reason for the elderly to participate in morning running lies in the time factor and the life style formed from it. Most of the elderly have formed a healthy lifestyle of going to bed early and getting up early. Moreover, the elderly have more time than the young people, so they don't have to rush to work. Therefore, the elderly can leisurely carry out morning running or go out to participate in tourism type events in their own way.

\section{References}

[1] Matthew Steven Krantz, Benjamin Wade Frush (2020). How to run a case: a guide for the resident at morning report. Postgraduate Medical Journal, (9): 25.

[2] Courteney L. Benjamin, William M. Adams, Ryan M. Curtis, Yasuki Sekiguchi, Gabrielle E. W. Giersch, and Douglas J. Casa (2018). Early Morning Training Impacts Previous Night's Sleep in NCAA Division I Cross Country Runners. Women in Sport and Physical Activity Journal, (5): 30.

[3] Malinowski, (2009). Voyagers in the Western Pacific. Translated by Zhang Yun-yuan. Beijing: China Social Sciences Press: 13-18.

[4] Clifford Geltz, (2014). Interpretation of culture. Translated by Han Li. Nanjing: Yilin Publishing House: 25-29.

[5] Li Mengdi, Shi Shu, (2019). Geertz's "deep description" theory: cultural research methods and its significance. Knowledge and practice, 37 (2): 147-150.

[6] Barranco-Ruiz Yaira, Guevara-Paz Alfredo Xavier, Ramírez-Vélez Robinson, Chillón Palma, and Villa-González Emilio (2018). Mode of Commuting to School and Its Association with Physical Activity and Sedentary Habits in Young Ecuadorian Students. International journal of environmental research and public health, (11): 30 .

[7] Mattias Qviström (2016). The nature of running: On embedded landscape ideals in leisure planning. Urban Forestry \& Urban Greening, (6): 20. 
[8] Lu Yuan Zhen, (2018). Sociology of sports. Beijing: Higher Education Press: 42-45.

[9] Justin W. L. Keogh, Nicola Power, Leslie Wooller, Patricia Lucas, Chris Whatman (2014). Physical and Psychosocial Function in Residential Aged-Care Elders: Effect of Nintendo Wii Sports Games. Journal of Aging and Physical Activity, (4): 29.
[10] Wang Da Zhao, (2010). Middle aged and elderly people become the main force of regular exercise crowd. People's daily, 2010-9-20.

[11] Clifford Geltz, (2004). Local knowledge: An Anthology of hermeneutic anthropology. Beijing: Central Compilation Bureau: 78-80. 